\begin{tabular}{|c|c|c|}
\hline & $\begin{array}{c}\text { PORT SAID ENGINEERING RESEARCH JOURNAL } \\
\text { Faculty of Engineering - Port Said University } \\
\text { Volume 17 No. 1 pp: 13:22 }\end{array}$
\end{tabular}

\title{
Analysis and Control of Liquefied Natural Gas Tanks Seismic Response
}

\author{
Lotfie Abdel-Latif*, Anwar Kandil**,Ebtisam Abdel-Gwad***, and Ayman Asaad***** \\ * Em. Prof, Mechanical Design Dept., Faculty of Engineering, Matareia, Helwan University. \\ ** Em. Prof, Production Eng. and Mech. Design Dept., Faculty of Engineering, Port Said University. \\ *** Assoc. Prof, Production Eng. and Mech. Design Dept., Faculty of Engineering, Port Said University. \\ **** Section Head of Canal CNG Stations, NGV Company (Car Gas), Egyptian Petroleum Ministry.
}

\begin{abstract}
Seismic response of liquefied natural gas tanks (LNG) is quite different from other structures not only due to hydrodynamic effects acting on the tank shell but also due to many sources of nonlinear behavior mechanisms of tanks. In this paper, the main seismic responses such as base force and overturning moment of conventional and isolated LNG tanks are investigated. Isolation system applied in this study is Friction Pendulum Bearing ${ }^{\mathrm{TM}}$ (FPB) that is installed between the tank and its foundation to protect it from damage due to earthquake shaking. Different parameters such as aspect ratio, coefficient of friction, and periodic time have been changed to study their effect on the seismic behavior of the LNG tank. FPB significantly reduces the main responses of the tank and so results reveal that the FPB seismic isolation system is very effective for using in LNG tanks.
\end{abstract}

Key words: LNG tanks, Seismic analysis, FPB isolation system, Base force, Overturning moment, and Aspect ratio.

\section{Introduction}

The seismic performance of LNG storage tanks has been a matter of special importance, beyond the economic value of the structure, due to the requirement to remain functional after a major earthquake event [1].

Investigations on the seismic response of liquid storage tanks have been conducted over the past 30 years [2]. The seismic analysis of such structures is a complicated and challenging task since complex actions must be taken into account. First of all, the contained liquid is interacting with the tank wall.

Seismic energy is transferred from the ground to the fluid through the tank motion [3]. A portion of the liquid accelerates with the tank, acting as an added mass; the remaining liquid is assumed to slosh [3]. Sloshing occurs in the upper part of the liquid, which does not displace laterally with the tank wall, generating seismic waves [4].

Failure of these tank facilities may cause life threatening fire or explosion, severe environmental damage and significant financial loss. Many LNG storage tanks, as a part of complex urban lifeline systems, require special considerations in their design to resist seismic loads [5].

Corresponding author: E-mail address: lotlatif2014@ gmail.com
In this paper a model of LNG cylindrical steel tank with inside diameter of $74 \mathrm{~m}$, height of $40.6 \mathrm{~m}$ and wall thickness of $21 \mathrm{~mm}$ is considered to study the seismic response. Roof of tank consists of stiffened steel plates supported on roof truss. Fig.1 shows the main dimensions of the LNG tank as well as the directions of the seismic base force and overturning moment. Tank was filled with LNG liquid of specific gravity (Relative density) 0.471 up to a height of $37.4 \mathrm{~m}$. Tank has a base plate of $5 \mathrm{~mm}$ thickness supported on hard soil. Specific weight of steel plates is $78 \mathrm{kN} / \mathrm{m}^{3}$.

One of the basic aims of this study is to evaluate the capability of the FPB seismic isolation system to decouple the LNG tank from the damaging effects of earthquake ground acceleration and reduce seismic forces and moments on the structures.

\section{FPB Isolation System}

In order to reduce the transmission of the earthquake motion to the structure, in most applications an isolation system is placed at the base of the structure and is thus referred to as base isolation [6].

The concept key of seismic isolation is to shift the fundamental period of the supported structure away from the dominant period range of most earthquake ground 
motions, so as to reduce seismic demands on the structural elements [7]. The reduction in acceleration demand can be achieved by introducing isolators in a horizontal plane, usually at the base of the structure, which exhibit very low horizontal stiffness. Isolators dissipate energy through friction or hysteretic damping, serving to control the displacements around the isolation interface [8]. Friction Pendulum Bearings are seismic isolators that are installed between a structure and its foundation to protect it from damage due to earthquake shaking. The bearings reduce lateral loads and shaking movements transmitted to the structure [9]. They can protect structures and their contents during strong earthquakes.

FPB use the characteristics of a pendulum to lengthen the natural period of the isolated structure so as to avoid the dangerous earthquake forces. The period of the bearing is selected simply by choosing the radius of curvature of the concave surface [9] and friction coefficient between the mating surfaces affects the amount of energy that can be dissipated by the FPB isolation system. It is independent of the mass of the supported structure. Torsion motions of the structure are minimized because the center of stiffness of the bearings automatically coincides with the center of mass of the supported structure. Dynamic frictions from $3 \%$ to $20 \%$ are available [7].

The FPB comprises three cast steel components, namely the housing plate, the concave plate and the slider [9], as shown in Fig. 2.LNG tanks are a strong candidate for application of seismic protective systems, especially using seismic isolation, due to the strict design requirements enforced by applicable codes. Moreover, the fundamental frequency ranges usually between 2 and $10 \mathrm{~Hz}$, placing them in the period range of strong earthquake shaking.

In this study, the LNG tank is supported on 94 units of FPB with a radius of curvature of $1880 \mathrm{~mm}$ and maximum horizontal stroke of $300 \mathrm{~mm}$. The isolated period is $2.75 \mathrm{sec}$. Two geometrical FE models have been used. First model without isolation system is conventional tank. Second FE model (isolated tank) includes the seismic isolators at the tank base. The bearings are assumed to have infinite vertical stiffness. Based on this assumption, the displacement restraint in the direction of the earthquake excitation, imposed at the base of the tank walls, was relaxed and horizontal nonlinear springs were introduced to connect the base of the walls to the ground.

ANSYS software has been used to model the FPB seismic isolation system at the tank base. ANSYS deals with FPB as truss elements and can incorporate material nonlinearity. A bilinear behavior with kinematic hardening was used to represent the nonlinear behavior of the isolation system.

\section{Numerical Seismic Performance}

When a tank containing liquid with a free surface is subjected to horizontal earthquake ground motion, tank wall and liquid are subjected to horizontal acceleration. The liquid in the lower region of tank behaves like a mass that is rigidly connected to tank wall. This mass is termed as impulsive liquid mass which accelerates along with the wall and induces impulsive hydrodynamic pressure on tank wall and similarly on base.

Liquid mass in the upper region of tank undergoes sloshing motion. This mass is termed as convective liquid mass and it exerts convective hydrodynamic pressure on tank wall and base. The results of the nonlinear response analyses are presented in the following section for the earthquake ground motions and the numerical models considered.

Table 1: Abbreviations used in case studies

\begin{tabular}{|c|c|}
\hline Term & Refers to: \\
\hline ANSYS & $\begin{array}{l}\text { Results Extracted from ANSYS-12 } \\
\text { Software }\end{array}$ \\
\hline SRSS & $\begin{array}{l}\text { Square Root of Sum of Squares } \\
\text { Method }\end{array}$ \\
\hline IMP & Results due to LNG Impulsive Mass \\
\hline CONV & Results due to LNG Convective Mass \\
\hline OBE & $\begin{array}{l}\text { Results According to Operating Basis } \\
\text { Earthquake }\end{array}$ \\
\hline SSE & $\begin{array}{l}\text { Results According to Safe Shutdown } \\
\text { Earthquake }\end{array}$ \\
\hline
\end{tabular}

SRSS, IMP, and CONV results have been calculated according to the mathematical equations of (API 650, 2007). As defined in NFPA 59A (2001), OBE presents the design requirements for operating conditions with no damage is accepted during return periods of 475 years. In SSE, limited damage is generally accepted during return periods of 2500 years.

\subsection{Conventional Case}

Case I presents Conventional LNG tank without isolation system. The maximum response magnitudes for $\mathrm{OBE}$ level of shaking are plotted in Figures 3 and 4.

Fig. 3 shows the maximum base shear obtained on the conventional construction LNG tank (without base isolation) for OBE shaking. Fig. 4 shows the maximum overturning moment obtained on the conventional construction LNG tank for OBE shaking. 
There is a good agreement between the results obtained from the ANSYS and SRSS numerical models. The response is dominated by the contribution of the impulsive hydrodynamic pressures exerted on the tank walls, as indicated in Figures 3 to 6. Convective pressures contribute less than $10 \%$ to the total response due to the long period of the first sloshing mode. Even when the convective effects are neglected (results noted as IMP), the base shear and global overturning moment can be predicted with almost the same accuracy as SRSS calculations.

\subsection{Isolated Cases}

Case II presents an isolated tank with periodic time 2 sec., while case III presents and isolated tank with periodic time $3 \mathrm{sec}$. isolated cases have been analyzed using OBE shaking technique. Figures 5 and 6 summarize the max. base shear force and max. overturning moment of LNG tank.

\section{Effect of Different Parameters}

\subsection{Aspect Ratio}

Tank Aspect Ratio is LNG fluid height to tank radius ratio $(\mathrm{H} / \mathrm{R})$. It is significant in the overall design of the tank. In order to study the behavior of LNG tanks for a wide range, the effect of changing aspect ratio values from 0.5 to 3.0 on the peak response quantities are shown in Figs.7, 8 , and 9. Base shear is an estimate of the maximum expected lateral force that will occur due to seismic ground motion at the tank base. The seismic base shear force $(\mathrm{V})$ is defined as the SRSS combination of the impulsive $\left(\mathrm{V}_{\mathrm{i}}\right)$ and convective $\left(\mathrm{V}_{\mathrm{c}}\right)$ components with the following equation [API 650, 2007]

$$
V=\sqrt{V_{i}^{2}+V_{c}^{2}}
$$

Fig. 7 shows the relation between aspect ratio and base shear over total tank weight $(\mathrm{V} / \mathrm{W})$. It is observed that the base shear force of the conventional tank is very sensitive to the change of the aspect ratio. On the other hand, using the FPB isolation system considerably reduced the base shear. Moreover, the base shear of isolated tanks is not significantly influenced by the aspect ratio. The LNG fluid can result in displacements in tank walls. Displacements in tank walls called impulsive displacement $\left(\mathrm{X}_{\mathrm{i}}\right)$ and convective displacement $\left(\mathrm{X}_{\mathrm{c}}\right)$ due to the LNG impulsive and convective components respectively. One can observe from fig. 8 that the impulsive displacement $\left(\mathrm{X}_{\mathrm{i}}\right)$ of the conventional tank considerably increases with higher aspect ratio. An advantage for using the FPB isolation system is that a low increasing in displacement which leads to reduce probability of local buckling in tank wall.
Fig. 9 also shows that in general the convective displacement $\left(\mathrm{X}_{\mathrm{c}}\right)$ increases with the aspect ratio of the tank with aspect ratio below 1 . For aspect ratios higher than 1, height of the tank should be increased to reduce the convective displacement value and hence, prevent spillage of the contained liquid or extra forces acting on tank roof.

\subsection{Friction Coefficient of FPB}

The effect of friction coefficient, $\boldsymbol{\mu}$ between the mating surfaces i.e. the slider and housing plate as well as concave plate of FPB, on the resulting response of isolated tank is shown in Fig. 10. Generally, increasing of the friction coefficient dissipates more seismic energy and hence causes decreasing in base shear over weight $(\mathrm{V} / \mathrm{W})$.

\subsection{Periodic Time of FPB}

Periodic time is the time needed to complete one complete cycle of vibration. Figs. 11 and 12 show the variation of peak responses of tank against the isolation period. Under periodic time of 3.5 sec., by increasing periodic time, an increasing of flexibility is noticed and the shear base and convective displacement are reduced because of transmitting less earthquake acceleration to the tank structure. Consequently, it is recommended to use the FPB with periodic time equal to 3.5: $4 \mathrm{sec}$. because of the smallest shear force and acceptable convective displacement.

\section{Advantages of Isolated Tanks}

To provide insight into effect of the seismic isolation system on changing responses of the LNG tank, Figs. 13 and 14 present the maximum base shear force and overturning moment for the conventional and two isolated cases.

The results reveal that seismic isolation significantly reduces the seismic responses of the LNG tank. The mean reduction of the base shear is $79 \%$ and $83 \%$ for case II and case III isolation system, respectively. For the same earthquake intensity, the overturning moment is reduced by $81 \%$ and $84 \%$ for the two isolation systems. The 3 -sec. proved a slightly higher response than the 2 -sec. FPB isolation system.

The isolated tank model with FPB units at the tank base is shown in fig. 15. 


\section{Conclusion}

1. In this paper, the isolation system (FPB) is used to reduce the transmission of the catastrophic earthquake motion to the LNG tank.

2. The FE model of the LNG tank is modified to introduce the seismic isolators at the base of the structure using ANSYS 12 Software. It may be noted that for the present steel tank, the pressure due to wall inertia is neglected because its effect is very small compared to impulsive hydrodynamic pressure.

3. Two cases of tanks are studied, conventional tank and base isolated tank. The main responses of the tank are calculated for each case, the maximum base force and maximum overturning moment.

4. Total base shear at the bottom of tank wall and total bending moment has been obtained by combining the base shear in impulsive and convective modes through Square Root of Sum of Squares (SRSS) rule and ANSYS 12.

5. The contribution of the impulsive and convective hydrodynamic pressures exerts on the tank walls is presented. Different parameters such as aspect ratio, coefficient of friction, and periodic time have been changed to study their effect on the seismic behavior of the LNG tank.

6. Results reveal that the FPB seismic isolation system significantly reduces the response of the tank. The mean reduction of the base shear is $79 \%$ and $83 \%$ for the 2 -sec. and the 3 -sec. periodic time isolation systems, respectively.

7. For the same earthquake intensity, the overturning moment is reduced by $81 \%$ and $84 \%$ for the two different periodic time isolation systems. The 3 -sec. FPB isolation system provides a slightly higher response to FPB than the 2-second isolation system.

\section{References}

[1] J. R. Cho, H. W. Lee and K. W. Kim, "Free vibration analysis of baffled liquid storage tanks by finite element formulation," Journal of Sound and Vibration, vol. 5: Elsevier Science Ltd., 2002, pp. 847-866.

[2] I. Nachtigall, N. Gebbeken, and J. Luis, "On the analysis of vertical circular cylindrical tanks under earthquake excitation at its base," Journal of Engineering Structures, vol. 25: Elsevier Science Ltd., 2003, pp. 201-213.

[3] F.H. Hamdan, "Seismic behaviour of cylindrical steel liquid storage tanks," Journal of Constructional Steel
Research, vol. 53: Elsevier Science Ltd., 2000, pp. 307-333.

[4] H. Sezen, R. Livaoglu, and A. Dogangun, "Dynamic analysis and seismic performance evaluation of above-ground liquid-containing tanks," Journal of Engineering Structures, vol. 30: Elsevier Science Ltd., 2008, pp. 794-803.

[5] H. Herna, E. Zavoni, and A. Rodriguez, "Nonlinear sloshing response of cylindrical tanks subjected to earthquake ground motion," Journal of Engineering Structures, vol. 29: Elsevier Science Ltd., 2007, pp. 3364-3376.

[6] A. Attari, and R. Rofooei , "On lateral response of structures containing a cylindrical liquid tank under the effect of fluid/structure resonances," Journal of Sound and Vibration, vol. 318: Elsevier Science Ltd., 2008, pp. 1154-1179.

[7] K. Shrimali, and S. Jangid, "Seismic analysis of baseisolated liquid storage tanks," Journal of Sound and Vibration, vol. 275: Elsevier Science Ltd., 2004, pp. $59-75$.

[8] Y. Tang, and C. Grandy and R. Seidensticker, "Seismic response of annular cylindrical tanks," Journal of Nuclear Engineering and Design, vol. 240: Elsevier Science Ltd., 2010, pp. 2614-2625.

[9] R. Shekari, and N.Khaji and T.Ahmadi, " On the seismic behavior of cylindrical base-isolated liquid storage tanks Excited by long-period ground motions," Journal of Soil Dynamics and Earthquake Engineering, vol. 30: Elsevier Science Ltd., 2010, pp. 968-980.

[10] S. Feible, "Technical characteristics of friction pendulum bearings", Earthquake Protection Systems, Inc., California 94592, 2003, USA. 


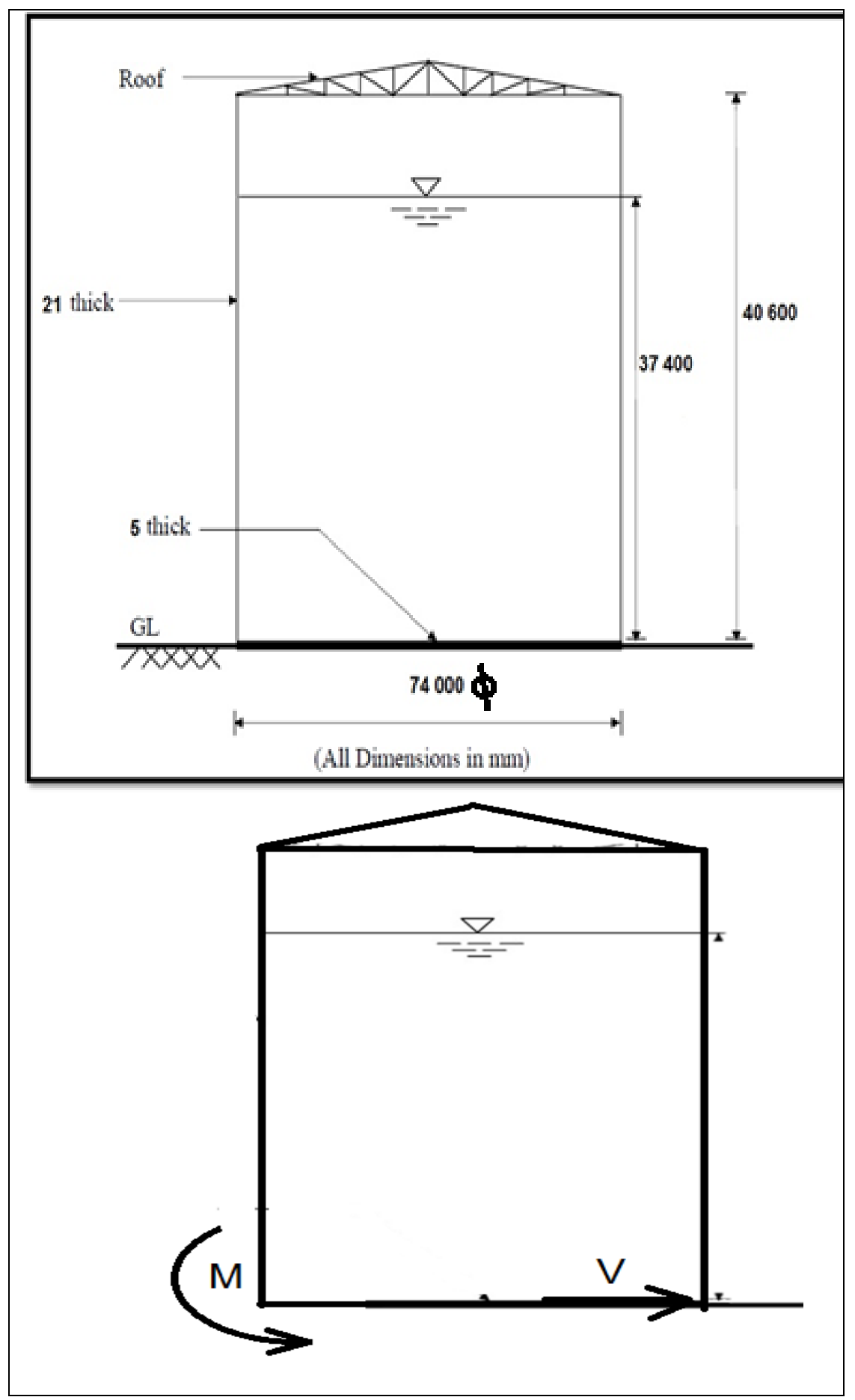

Fig. 1 the main dimensions of the LNG tank and directions of base force (V) and overturning moment (M) 


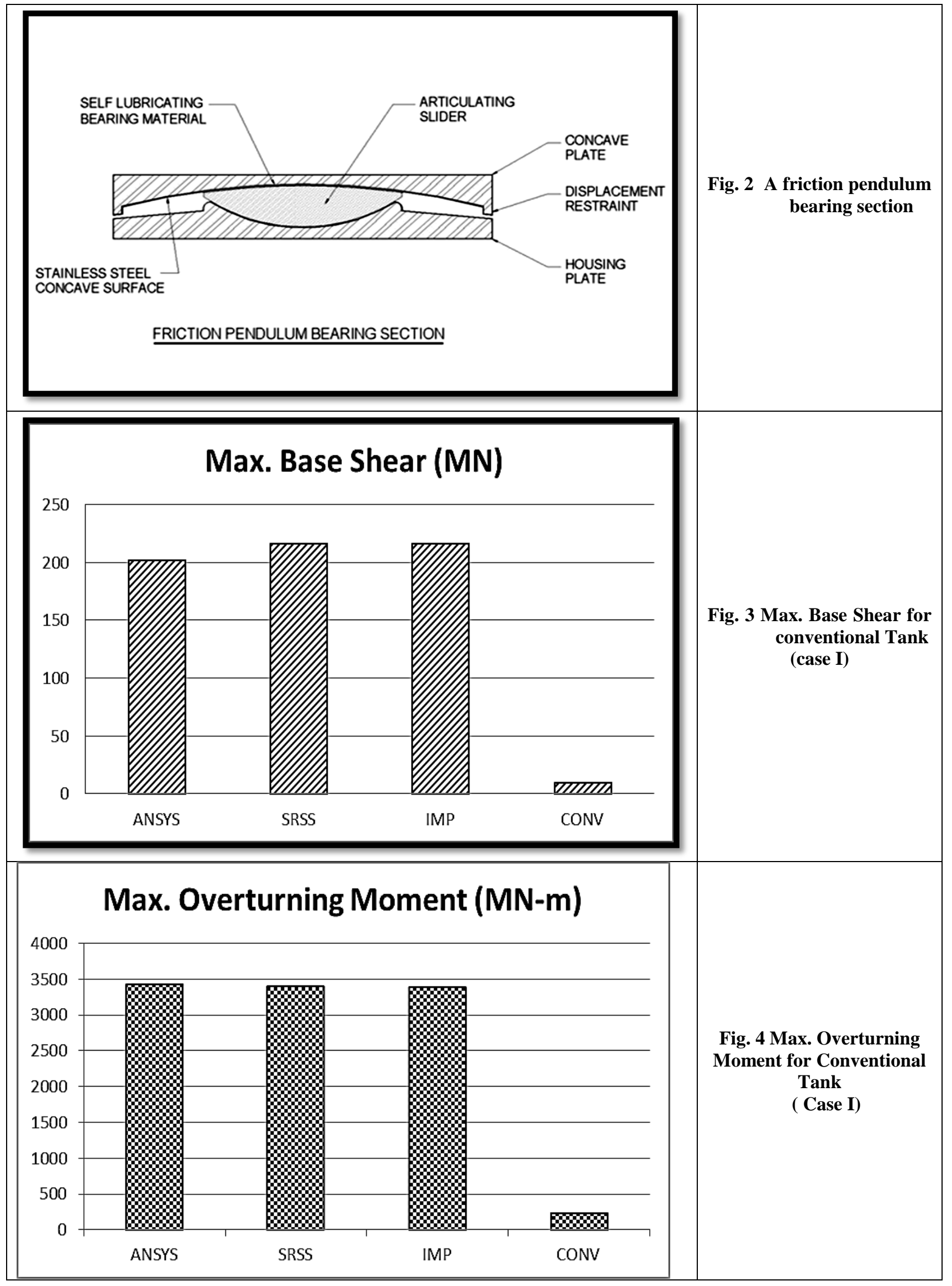




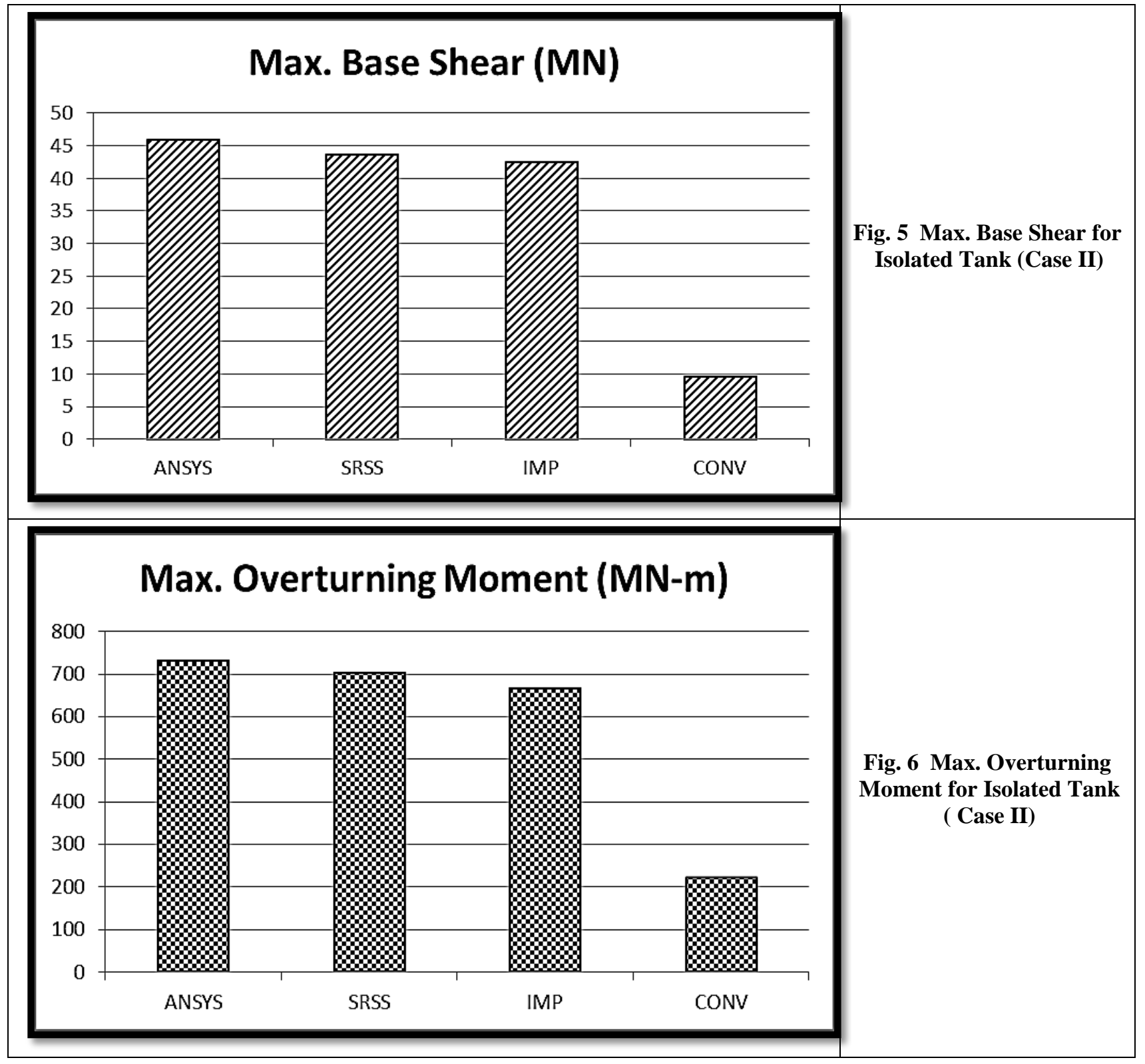




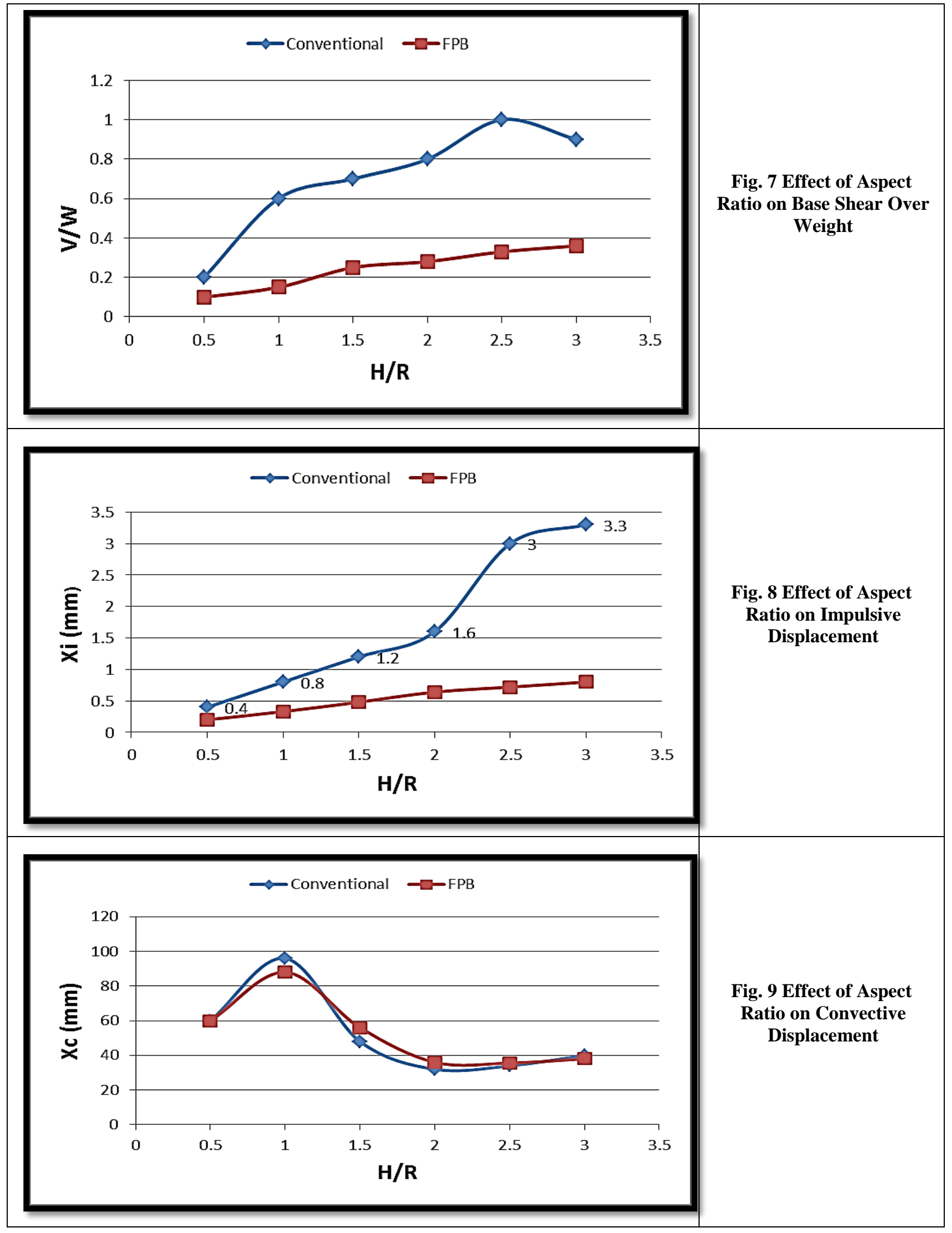




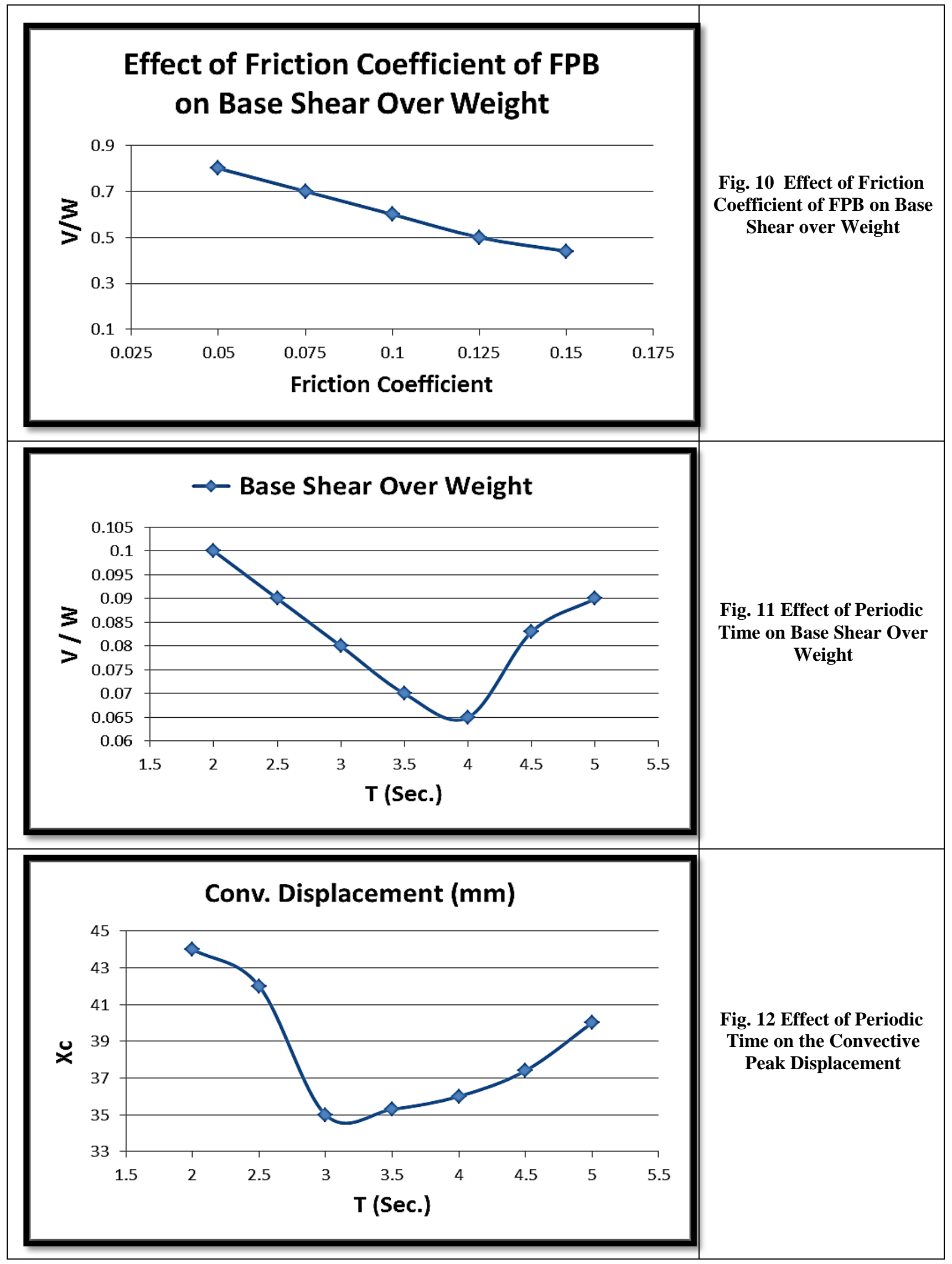




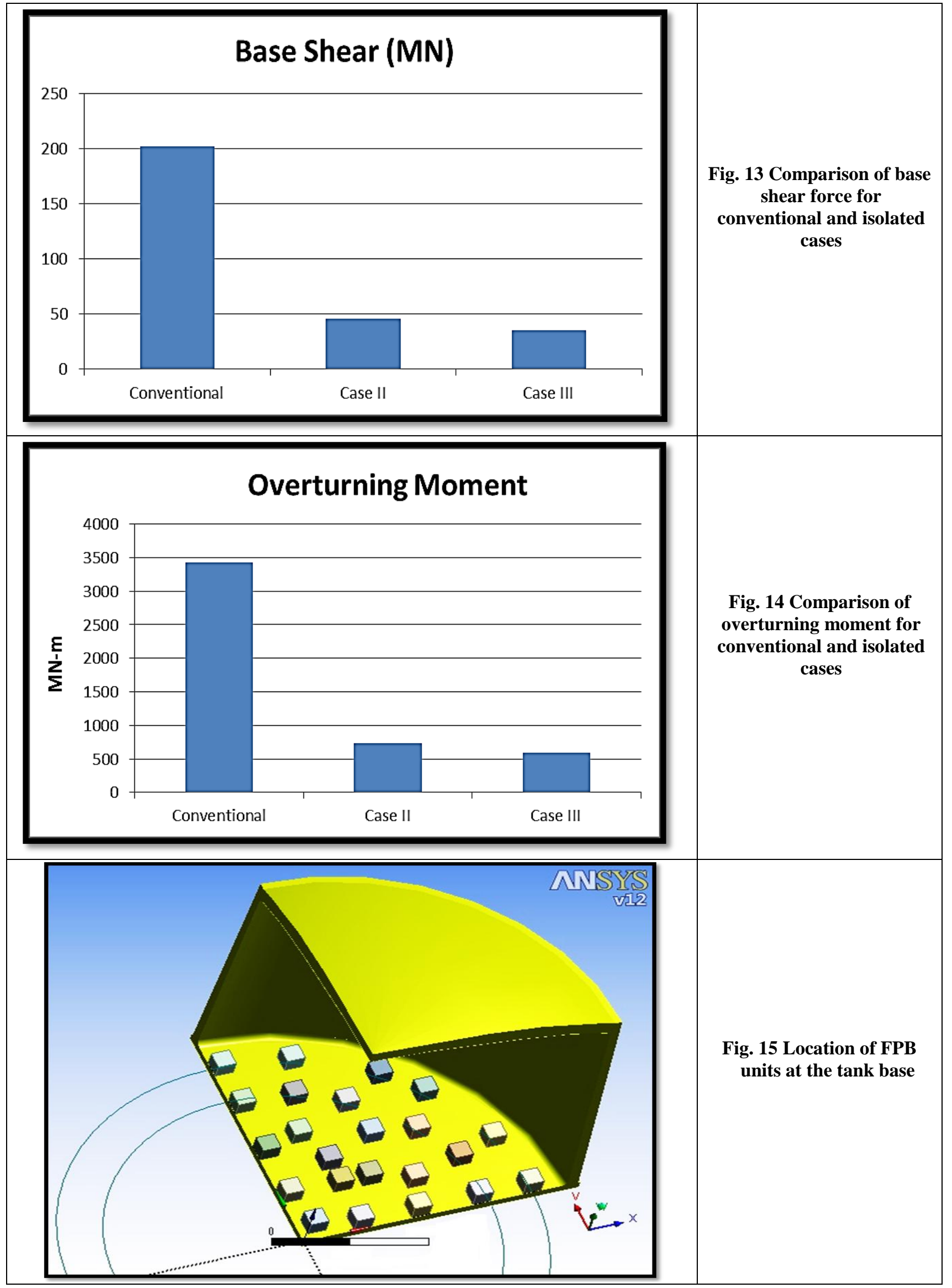


